
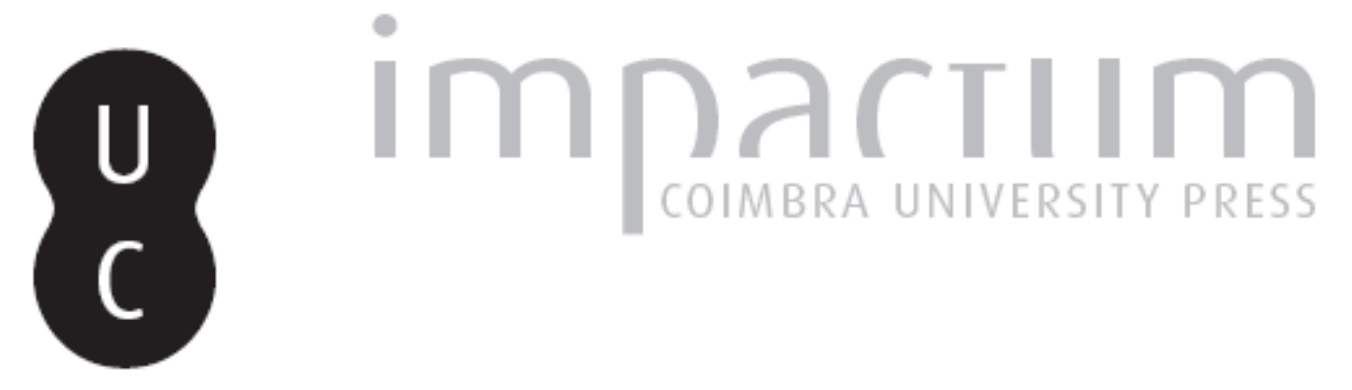

\title{
Lisboa insubmissa diante de Filipe II
}

\section{Autor(es): Miranda, Margarida}

Publicado por: Imprensa da Universidade de Coimbra

URL persistente:

URI:http://hdl.handle.net/10316.2/34007

DOI:

DOI:http://dx.doi.org/10.14195/0872-2110_58_11

Accessed : $\quad$ 26-Apr-2023 16:33:56

A navegação consulta e descarregamento dos títulos inseridos nas Bibliotecas Digitais UC Digitalis, UC Pombalina e UC Impactum, pressupõem a aceitação plena e sem reservas dos Termos e Condições de Uso destas Bibliotecas Digitais, disponíveis em https://digitalis.uc.pt/pt-pt/termos.

Conforme exposto nos referidos Termos e Condições de Uso, o descarregamento de títulos de acesso restrito requer uma licença válida de autorização devendo o utilizador aceder ao(s) documento(s) a partir de um endereço de IP da instituição detentora da supramencionada licença.

Ao utilizador é apenas permitido o descarregamento para uso pessoal, pelo que o emprego do(s) título(s) descarregado(s) para outro fim, designadamente comercial, carece de autorização do respetivo autor ou editor da obra.

Na medida em que todas as obras da UC Digitalis se encontram protegidas pelo Código do Direito de Autor e Direitos Conexos e demais legislação aplicável, toda a cópia, parcial ou total, deste documento, nos casos em que é legalmente admitida, deverá conter ou fazer-se acompanhar por este aviso.

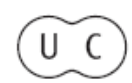


COIMBRA • 2013
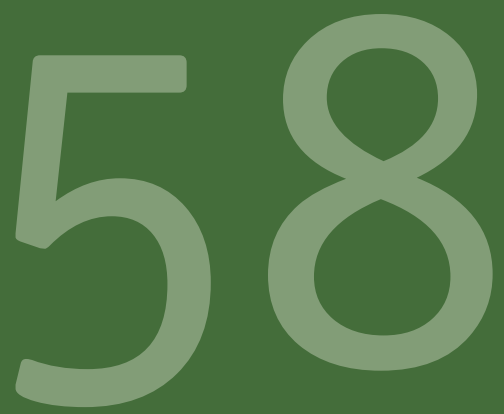

BOLETIM DE

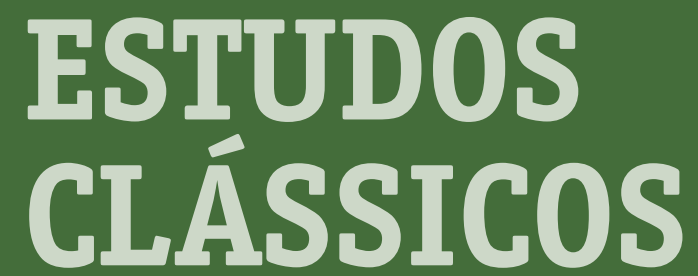

\author{
ASSOCIAÇÃO \\ PORTUGUESA \\ DE ESTUDOS \\ CLÁSSICOS \\ INSTITUTO \\ DE ESTUDOS \\ CLÁSSICOS
}




\title{
Lisboa insubmissa diante de Filipe II (1619)
}

\author{
MARGARIDA MIRANDA
}

A Tragicomédia do rei Dom Manuel, do jesuíta António de Sousa, representada em Lisboa em 1619 no Colégio de Santo Antão, foi uma das mais notáveis representações jesuíticas de sempre. Preparada para receber a visita de Filipe II a Lisboa, a sua representação estendeu-se ao longo de dois dias e foi considerada sem rival em qualquer corte europeia. No entanto, ela representava o culminar de uma já longa tradição de fausto e grandiosidade, nos palcos jesuíticos portugueses.

Se de um modo geral, as representações teatrais dos Colégios eram vistas como meios de promover o bom nome dos Colégios, com mais razão ainda esta representação tinha em vista agradar e impressionar não a cidade mas o próprio monarca Filipe III de Espanha, e a sua corte, naquela que era a primeira e única visita a Lisboa, ao cabo de insistentes pedidos do reino, após cerca de vinte anos de governação ausente.

Os festejos com que a cidade recebeu o monarca no Terreiro do Paço foram verdadeiros triunfos, mas o recebimento no Colégio de Santo Antão não foi menos solene. Foi principalmente ambíguo. A Tragicomédia do Rei Dom Manuel foi uma cerimónia onde predominou o tom festivo pela solenidade do acontecimento sem que, ao mesmo tempo, deixassem de se multiplicar as mais surpreendentes manifestações anti-filipinas, expressão do crescente descontentamento gerado em Portugal pela insatisfação da governação espanhola, pelas dificuldades económicas e pela permanente ausência do rei e da corte. Assim, a arte com que António de Sousa dá voz ao orgulho pátrio e às expectativas do reino fazem da Tragicomédia do Rei Dom Manuel uma peça exemplar de literatura auto- 
nomista. Ao mesmo tempo que saúda Filipe II como Monarca do mundo, Lisboa lembra-lhe as glórias de D. Manuel, a quem o soberano deve a sua própria majestade e de quem deve aprender todas as virtudes.

O assunto da tragicomédia não é de todo inócuo. Os Descobrimentos e as conquistas do Oriente pelos portugueses, no reinado de D. Manuel, permitiram apresentar diante do Monarca um espectáculo que mais não foi do que a glorificação de Portugal. Filipe III de Espanha (II de Portugal) fez a sua entrada em Lisboa com uma cerimónia em tudo análoga às tradicionais entradas régias da História, mas foi recebido com um espectáculo inteiramente dedicado à celebração das grandezas lusas. A leitura das palavras iniciais de Lisboa, no Prólogo são marcadas por uma visível altivez, dissimulada de saudação devota ao monarca espanhol. Em vez do gesto de vassalagem para com o mais ilustre dos seus visitantes, o que predomina na fala de Lisboa é a afirmação da sua majestade; majestade que não podia deixar de transparecer na caracterização exterior da própria figura. Na peça figuravam mais de 300 personagens, com um guarda-roupa de uma riqueza oriental deslumbrante, carregado de pedras preciosas, 1090 diamantes, 3000 pérolas, 248 esmeraldas, 1139 rubis, velhos brocados históricos, sedas raras e adereços preciosos emprestados pela família real e pelas casas de fidalgos, assim como pelas igrejas e mosteiros. A cenografia era grandiosa e a complicação da maquinaria excedia tudo o que até então se havia vistoํ.

2800 pedras adornavam a figura de Lisboa a quem coube a representação do Prólogo, juntamente com as alegorias de Sintra e do Tejo.

1 Sardinha Mimoso (1620), Relación de la Real Tragicomédia com que los Padres de la Compañia de Jesus en su Colégio de S. Anton de Lisboa recebieron a la Magestad Católica de Filipe II de Portugal... Impresso en Lisboa por Jorge Rodriguez. Uma análise minuciosa deste acontecimento foi feita por Dietrich Briesemeister, (2006), "O Teatro escolar jesuítico e os Descobrimentos Portugueses: António de Sousa e La Real Tragicomedia del Rey Dom Manoel" in Sebastião Tavares de Pinho (Coord.) Teatro Neolatino em Portugal no Contexto da Europa. Coimbra: 127-142. Analisou também cuidadosamente esta obra dramática, Cecília Pires (2010) A Real Tragicomédia do Rei Dom Manuel, de António de Sousa, um modelo de literatura independentista. Coimbra, em tese de Mestrado que tive o grato prazer de orientar. 
Os versos que a seguir se transcrevem pertencem à Cidade de Lisboa e são um excelente testemunho do sentimento de orgulho nacional que a peça encerra, bem diferente do gesto de vassalagem que esperaríamos dos súbditos portugueses. Lisboa é em tudo Domina, Rainha, Senhora; é a soberana majestosa por excelência, como reflectem os milhares de jóias que a cobrem. Assim, as primeiras palavras que dirige ao Monarca são para lembrar o poder que ela própria tem exercido, contra a altivez de reis poderosos, cujos ceptros esmagou vencedora!

E é esta Lisboa confiante, soberana e quase ameaçadora que, em nome do reino, pretende pedir ao rei que transfira para Portugal o privilégio da capital do Reino. Na verdade, Lisboa não suplica; ela oferece, antes, ao Monarca a dignidade de tornar para ele o trono real, prometendo emprestar-lhe, com isso, maior celebridade. Afinal, quem não conhece Lisboa? Pode-se percorrer ao acaso o orbe inteiro, que até os bárbaros etíopes, na sua rude língua, sabem pronunciar o seu nome. Como a palma verdejante se ergue na encosta contra forças adversas, assim se ergue Lisboa, poderosa, nutrida das mais árduas batalhas.

A personagem de Lisboa concebida por António de Sousa para o solene recebimento do Monarca Filipe II de Portugal III de Espanha, ousa declarar ao 'Monarca do Mundo' que aquela Rainha majestosa, que tem diante de si, ao qual o orbe inteiro conhece, a jugo algum dobrará a sua cerviz, a menos que o queira.

Estas são as palavras desassombradas do Prólogo diante de Dom Filipe. É caso para perguntar: saberia Latim, o Monarca? 
1 Assueta plantis fortium Regum meis calcare fastus, sceptra ceruices premo generosa duras exterae gentis, pede uictore, dites semper exuuias ferens

5 annosa quas non saecula refigent manu [...]: $\quad$ surgo potens nutrita bellis arduis; palma ut uirens dorso resurgit pondus aduersun graue. Olisiponem quisquis ignorat uagum

10 percurrat orbem: hoc nomen incultus rudi formare uocis Aethyops nouit sono: didicere primum Regna quae Solem uident, et quicquid alto uertice reuisit polus Dominam uocare didicit Oceano, caput

15 nulli daturam sponte nisi uolet iugo hoc nomen exteri dabant, qui olim mihi, quam nunc uocabunt? Viderint si urbem suis orbem tenere manibus? Dominam uocat quicunque nomen clarius posthac sciet

20 urbi futurum, nuncupet Regis torum, dominator orbis fixit ubi signum pede, meus Philippus, splendor, \& Regni iubar, solium uocabor. Restat hoc maius? Dabit maiora quisquam? Nemo, nec maius uolo.

25 Aperire corde gaudium inclusum iuuat; gratentur urbis incolae fastam diem, extremus orbis sentiat; dum artus reget animus triumphans, hanc diem gemmae notent. (Prólogo, vv. 1 - 28, fl. 7) 
1 Habituada a esmagar a meus pés a altivez de reis poderosos, sou detentora de nobres ceptros e da dura cerviz de gente estrangeira. Com meu pé vencedor, arrecadei sempre valiosos despojos

5 que nem séculos e séculos me hão-de arrancar com sua mão. [...]; Ergo-me, poderosa, de árduas batalhas nutridas, como a palma verdejante que se ergue na encosta, contra as forças adversas. Quem ignora Lisboa, percorra o orbe inteiro, ao acaso: este [meu] nome, sabe-o pronunciar o rude Etíope, com o bárbaro som da sua fala; Conheceram-no [igualmente] aqueles reinos que primeiro o sol avistam, e tudo quanto, lá do alto, a Estrela Polar alcança, aprendeu com o Oceano a chamar-me 'Rainha'

15 que a jugo algum dobrará sua cabeça, a menos que o queira. Esse nome, davam-me outrora os [povos] estrangeiros. Porém, que nome darão agora à cidade, quando perceberem que ela detém em suas mãos o poder do mundo inteiro? Todo aquele que Rainha me chama, conhecerá, a partir de hoje, 20 mais ilustre nome ainda, e chamará a esta cidade morada Real, onde o dominador do mundo fixou o seu estandarte, Filipe, meu [Senhor], esplendor e glória [deste] Reino. 'Trono', serei então chamada. Haverá porventura maior honra? Alguém me poderá dar maior dignidade? Ninguém. Nem eu posso desejar.

25 Muito me apraz, pois, revelar-vos a alegria que trago no coração! Exultem os habitantes [desta] cidade por este dia de alegria! Conheçam-no também as paragens mais remotas do mundo. Enquanto o espírito triunfante comandar [meus] membros, [assinalem estasjóias [que me cobrem] [a solenidade] deste dia. 